\title{
A ISONOMIA, O STF E O ART. 387 DA CLT - UMA ANÁLISE CRÍTICA DO RE 658312
}

\author{
ISONOMY, STF AND CLT, ART. 387 - A CRITICAL ANALYSIS OF RE 658312 \\ Rafael Diogo Lemos \\ Graduado em Direito (UNIFOR). Pós graduado lato sensu em Direito Processual Civil. \\ Mestre em Direito Constitucional (UFRN). E-mail: rafael.diogo@gmail.com
}

Recebido em: 07/12/2016

Aprovado em: 14/03/2017

RESUMO: O presente trabalho visa a analisar criticamente o recurso extraordinário 658312 e tecer considerações sobre a igualdade de gênero no mercado de trabalho e no Direito do Trabalho. Serão avaliados dados quantitativos da inclusão da mulher no mercado de trabalho, os principais elementos discriminatórios e as medidas legais usadas para o combate à discriminação. Será analisada a evolução do tratamento e da importância da mulher no mercado de trabalho e a necessidade de se promover à igualdade e perquirir a necessidade de um tratamento discriminatório positivo. Por último, será avaliada especificamente a norma do artigo 384 da CLT como medida protetiva ou discriminatória da mulher.

Palavras-Chave: Igualdade; Mulher; Mercado de trabalho; Relação de Emprego; Horas extras.

ABSTRACT: The present work aims to critically analyze the extraordinary resource 658312 and to make considerations on gender equality in the labor market and Labor Law. Quantitative data on the inclusion of women in the labor market, the main discriminatory elements and the legal measures used to combat discrimination will be evaluated. The evolution of treatment and the importance of women in the labor market and the need to promote equality and to look for the need for positive discriminatory treatment will be analyzed. Lastly, the standard of Article 384 of the CLT will be specifically evaluated as a protective or discriminatory measure for women.

Keywords: Equality; Woman; Job Market; Employment relationship; Overtime.

SUMÁRIO: Introdução. 1. O trabalho extraordinário no Direito brasileiro. 1.1 Compensação de jornada extraordinária - o "banco de horas". 1.2 A evolução legal da prestação da jornada de trabalho da empregada. 2. A mulher no mercado de trabalho - Dados estatísticos e análise do RE 658312. 2.1 Plano nacional de políticas públicas para as mulheres. 2.2 Os fundamentos esposados no RE 658312. 3. O conteúdo jurídico da igualdade e o discrímen legitimador de normas de desigualdade. Conclusão. Referências Bibliográficas.

\section{INTRODUÇÃO}

Aos catorze dias do mês de setembro do ano de 2016, o Supremo Tribunal Federal (STF) concluiu julgamento que iniciará há cinco anos, reforçando a constitucionalidade do artigo 384 da Consolidação das Leis Trabalhistas (CLT) que prega a obrigatoriedade de um intervalo de no mínimo quinze minutos antes do início do período extraordinário de trabalho para a mulher. 
Este entendimento mantém o posicionamento pacífico do Tribunal Superior do Trabalho (TST) que se baseia na igualdade material preconizada pela Constituição da República Federativa do Brasil (CRFB), entendendo haver uma relação lógica entre a discriminação de gênero e a dificuldade de acesso da mulher ao mercado de trabalho e à ascensão profissional com o tratamento diferenciado conferido pela legislação infraconstitucional, garantindo-lhe algumas vantagens necessárias à tentativa de eliminação das desigualdades entre homens e mulheres.

Sabe-se que a igualdade prevista na CRFB/88 não é absoluta e deve ser sopesada com critérios materiais e sociais que justificarão tratamento diferenciado a pessoas com necessidades específicas ou em situações distintas. $\mathrm{O}$ critério diferenciador deverá ser proporcional e consoante com os fundamentos constitucionais e apto a produzir os objetivos pretendidos pelo ordenamento jurídico para ser considerado legítimo e, portanto, de acordo com a ordem jurídica vigente.

Buscar-se-á, neste trabalho, analisar os fundamentos esposados no Recurso Extraordinário (RE) 658312, analisando a invocada distinção entre homens e mulheres suficientes a justificar a constitucionalidade do artigo 384 da CLT além de se perquirir a evolução da participação da mulher no mercado de trabalho e a justificativa atual da existência de tratamento discriminatório positivo à empregada.

Será explicado, inicialmente, o regime de sobrejornada previsto na legislação laboral pátria. Ato contínuo, serão avaliados dados atuais da mulher no mercado de trabalho, tais como diferença entre ocupação entre homens e mulheres, diferenças salariais, entre jornada de trabalho e, por último, diferenças biológicas sociais entre os sexos. Faz-se necessária a avaliação minuciosa destes dados pois foram os principais argumentos utilizados pelo STF para o entendimento da constitucionalidade do artigo supracitado.

Serão debatidos os principais argumentos trazidos pelos Ministros no julgamento do recurso extraordinário $\mathrm{n}^{\circ} 658312$ e avaliada se a norma inserta no artigo 384 da CLT atende, atualmente, ao postulado da proporcionalidade bem como se a medida não causa um efeito contrário, qual seja, o da limitação da participação da mulher no mercado de trabalho.

Por derradeiro, caberá o estudo sobre o postulado da igualdade e, mais especificamente, os critérios aplicados para a legitimação da desigualdade sob a ordem jurídico-constitucional brasileira.

\section{O TRABALHO EXTRAORDINÁRIO NO DIREITO BRASILEIRO}

A limitação da jornada de trabalho é um dos direitos que deram origem às primeiras revoluções sindicais. O Brasil passou a reconhecer a necessidade de uma limitação na jornada de trabalho na Constituição de 1934 e somente em 1940, foi unificado para todos os trabalhadores o limite de oito horas diárias e quarenta e oito horas semanais. A fixação da jornada de oito horas diárias e quarenta e quatro semanais ocorreu com a edição da CRFB/88.

O objetivo primordial é tutelar a integridade física e mental do trabalhador, possibilitando que este possa conviver com sua família e realizar atividades que não estejam vinculadas ao trabalho, reforçando seu convívio social e aprimorando as relações humanas. Há, também, conteúdos microeconômicos e macroeconômicos na limitação da jornada, de modo a manter uma maior produtividade dos trabalhadores, diminuir a incidência de acidentes de trabalho e estimular a contratação de mais trabalhadores para aquelas empresas que funcionam em turnos ininterruptos ou necessitam constantemente de horas extras de seus empregados.

A CLT fixou, basicamente, dois modelos distintos da realização de horas extras, que são nos casos de necessidade imperiosa ou a jornada meramente suplementar.

O artigo 61 da CLT aduz que poderá haver prorrogação na jornada de trabalho para fazer face a motivo de força maior, para atender à realização ou conclusão de serviços inadiáveis ou cuja inexecução possa acarretar prejuízo manifesto. 
A redação original do texto consolidado previa que a mulher só poderia ser submetida a jornada de trabalho extraordinária em caso de força maior. Todavia, a Lei 10.244/11 entendeu não haver mais necessidade nesta distinção e revogou o artigo 376 da CLT extinguindo esta diferenciação.

O limite da jornada de trabalho, em caso de força maior, é até doze horas, uma vez que deverá haver um intervalo interjornada de, no mínimo, onze horas.

Na hipótese de atendimento à realização ou conclusão de serviços inadiáveis, esta prorrogação justifica-se pelo período necessário ao atendimento dos serviços inadiáveis, com o limite de até doze horas, respeitando o intervalo mínimo de onze horas entre o término de uma jornada e o início da seguinte.

Ao lado destas possibilidades, a CLT possibilita o trabalho extraordinário, com o limite de duas horas diárias, quando houver acordo escrito entre empregado e empregador ou mediante contrato coletivo de trabalho. O artigo 59 da CLT, interpretado sistemicamente com o artigo $7^{\circ}$, XIII e XVI da CRFB/88, flexibiliza a jornada de oito horas diárias e quarenta e quatro horas semanais ao passo que permite uma ampliação potencial da jornada de trabalho para até dez horas diárias, desde que haja acordo firmado entre as partes e as horas extras sejam remuneradas com valor de no mínimo cinquenta por cento superior à hora normal. As horas extras prestadas habitualmente pelo empregado, entendendo-se como aquelas prestadas pelo período mínimo de um ano, incorporam-se à remuneração do empregado, sendo lícita sua supressão pelo empregador desde que haja indenização correspondente ao valor de um mês das horas suprimidas, total ou parcialmente, para cada ano ou fração superior a seis meses da prestação de serviço acima da jornada normal, consoante o enunciado sumular n. 291 do TST.

Nas hipóteses de sobrejornada nos locais em que se desenvolvem atividades insalubres, esta fica condicionada à licença prévia das autoridades competentes em matéria de segurança e higiene do trabalho, mediante exames locais. Há, também, a limitação à hora extra pelo menor, em caso de força maior e desde que seu trabalho seja imprescindível a funcionamento do estabelecimento. O artigo 62 da CLT excepciona das disposições legais os empregados externos que exercem atividade incompatível com a fixação de horário de trabalho e desde que não haja controle de jornada pelo empregador e os gerentes ou aqueles que exercem cargo de gestão, como os diretores e chefes de departamento ou filial bem como proíbe a realização de horas extras por empregados sob regime parcial.

\subsection{Compensação da jornada extraordinária - o "banco de horas"}

A Lei 9.601/98 surgiu como uma resposta à forte crise econômica vivida naquele ano no Brasil, e visando a findar debates doutrinários acerca da possibilidade da compensação na jornada de trabalho com base no art. $7^{\circ}$, XIII da CRFB. A lei instituiu o "banco de horas", permitindo que o trabalho extraordinário em um dia fosse compensado com a ulterior redução na jornada de trabalho, desde que fosse feito mediante acordo ou convenção coletiva, no período máximo de um ano e observado o limite de jornada de dez horas diárias.

A CLT e a CRFB usam distintamente os termos "convenção" e "acordo", referindo-se aquele às negociações coletivas e este às negociações individuais o que levaria ao entendimento de que a instituição do "banco de horas" legitimar-se-ia mediante acordo entre empregados e empregadores ou através de sindicatos. Todavia, o TST, por meio de seu enunciado sumular n. 85 pontuou ser inválida a instituição do "banco de horas" por meio de negociações individuais que deverá ser realizada através de convenções coletivas.

A submissão da instituição das horas extras a negociações coletivas previne uma excessiva precarização da relação de trabalho, criando-se uma espécie de escravidão moderna, em que os trabalhadores podem ser submetidos constantemente a jornadas extenuantes sem uma contraprestação pecuniária e com uma possível compensação ao final de um ano. A limitação da 
jornada e a remuneração maior das horas extras constituem uma nítida proteção ao trabalhador, protegendo sua integridade física, prevenindo doenças e acidentes relacionados ao trabalho e estimulando, ainda, a contratação de outros trabalhadores pelo empregador. As horas extras, assim, tem natureza indenizatória, recompensando o trabalhador pelo descanso, convívio familiar e lazer perdidos e pela sujeição a maiores riscos oriundos do trabalho excessivo.

A compensação de jornada de trabalho, como é admitida no direito brasileiro, é uma exceção no direito comparado. Enquanto alguns países a vedam expressamente (Itália, Argentina e Espanha, por exemplo), há aqueles que admitem a compensação com uma proporção de uma hora trabalhada para cada uma hora e meia compensada (Estados Unidos da América) e alguns que admitem a compensação através de negociações coletivas ou mesmo diretas entre empregados e empregadores (Portugal).

\subsection{A evolução legal da prestação da jornada de trabalho da empregada}

O artigo 372 da CLT estabelece que os preceitos que regulam o trabalho masculino deverão ser aplicáveis ao feminino, naquilo que não coincidirem com as condições especiais da trabalhadora. Este dispositivo foi recepcionado pela nova ordem constitucional que prega a igualdade entre homens e mulheres, garantindo-se a proteção do mercado de trabalho da mulher, mediantes incentivos específicos, nos termos da lei. Assim, aplicam-se à mulher as normas de limitação de jornada de trabalho explicitadas anteriormente.

No tocante à sobrejornada, A CLT estabelecia, em seus artigos 375 e 376, a proibição de sua realização pelas empregadas, salvo em casos excepcionais, por motivo de força maior e desde que autorizada por atestado médico oficial, constante de sua carteira profissional.

Tais disposições foram revogadas pela Lei 7.855/89, de modo a compatibilizar a legislação consolidada com a previsão de igualdade de todos perante a lei, sem distinção de raça, origem, cor ou sexo, de forma que toda regra que trata distintamente o homem e a mulher sem um critério legítimo de diferenciação, deverá ser considerado inconstitucional ou não recepcionado pela CRFB/88 (DELGADO, 2015). É neste sentido que são legitimadas as normas destinadas a corrigir as distorções que afetam o ingresso, a permanência e ascensão da mulher no mercado de trabalho bem como disposições específicas, como a proibição da exigência de atestado ou exame para comprovação de esterilidade ou gravidez, realização de revistas íntimas na empregada, dentre outras.

No tocante ao período de descanso, são previstos os mesmos direitos para o trabalho do empregado, com exigência de intervalo interjornada de no mínimo onze horas e intrajornada de pelo menos uma hora e não superior a duas horas e o repouso semanal remunerado, preferencialmente aos domingos. O artigo 384, todavia, impõe a exigência de intervalo de quinze minutos, no mínimo, entre o final da jornada de trabalho e o início da hora extraordinária, não prevendo igual direito para o empregado do sexo masculino.

Este dispositivo legal justificou-se em um período de gênese dos direitos das mulheres e da necessária igualdade nas relações trabalhistas. A CLT veio suplantar práticas discriminatórias institucionalizadas que previam salário inferior da empregada em comparação com o empregado nas mesmas condições (Decreto Lei 2.548/40) ou a determinação do Ministro da Educação Gustavo Capanema, no início da década de quarenta, que estabelecia que enquanto o homem deveria ser preparado para o militarismo, os negócios e as lutas, a educação da mulher deveria adaptá-la para a vida do lar (BORELLI, 2005). A recepção desta norma pela CRFB/88 e sua legitimação após setenta anos do adento do compêndio laboral devem ser sob o conteúdo ético da igualdade, em um século marcado pela eliminação das diferenças entre mulheres e homens e a progressiva erradicação do discurso de falta de oportunidades para as mulheres e do reconhecimento de que normas que preveem tratamentos diferentes para pessoas em igualdade de condições justificam-se, tão somente, quando aptas a alcançar um determinado fim ético ou 
social, observando-se o postulado da proporcionalidade e permeando o fator de discrímen com o conteúdo axiológico previsto pela ordem constitucional.

\section{A MULHER NO MERCADO DE TRABALHO - DADOS ESTATÍSTICOS E ANÁLISE DO RE 658312}

É usual a alegação da diferença existente entre os sexos no mercado de trabalho, remetendo à histórica dominação dos trabalhadores homens do mercado de trabalho, com salários mais elevados, mais e melhores empregos. A mensuração quantitativa da participação da mulher no mercado de trabalho não pode mais ser analisada de maneira isolada, sendo necessária sua análise qualitativa, com foco em produtividade e renda das mulheres quando comparadas com homens em empregos similares.

Desde a década de oitenta, há um aumento da participação da mulher no mercado de trabalho, diminuindo a diferença existente entre os gêneros em até dez pontos percentuais em trinta anos. As principais causas são o desenvolvimento econômico, melhoria na educação e declínio da taxa de fertilidade, tendo as alterações na legislação apenas impacto reduzido e, no mais das vezes, "homologatório" das mudanças sociais vividas pelos diversos países.(WORLD BANK ONLINE, 2012)

Com o incremento do desenvolvimento econômico, cresce o número de oportunidades para mulheres, especialmente nos setores de serviços e de manufatura. A melhoria na educação permite igual acesso ao aprimoramento profissional, possibilitando a competição técnica em igualdade com os homens e o declínio da taxa de fertilidade permite um menor tempo de afastamento da mulher do mercado de trabalho, em virtude da maternidade.

As mulheres também têm salários inferiores aos dos homens, aproximadamente, doze por cento, chegando a atingir a metade dos rendimentos dos empregados do sexo masculino no setor de serviços e de saúde e bem-estar social (IBGE, 2011).

A desigualdade de gênero foi reduzida no acesso, com regras proibindo atitudes discriminatórias, bem como no processo educacional que, por sua vez, consta uma superioridade de mulheres alunas de ensino superior (em média, quinze por cento das mulheres brasileiras frequentam o ensino superior frente a onze por cento de homens), mas estes números não favorecem as mulheres no mercado de trabalho.

A desejada autonomia, elemento indissociável da dignidade humana, não é totalmente possível às mulheres em razão do tratamento diferenciado no mercado de trabalho. A despeito da inegável progressão da participação da mulher no mercado de trabalho, o ideal da igualdade, objetivado pela CRFB/88 e perseguido por alguns setores da sociedade ainda não é uma realidade no Brasil.

\subsection{Plano nacional de políticas públicas para as mulheres}

Visando à erradicação das desigualdades e eliminação de práticas discriminatórias ilegítimas com base em gênero, a Secretaria Especial de Políticas para as Mulheres traça Planos, conjecturados através de diálogos entre a sociedade civil e o poder público, com esboços programáticos e trazendo resultados de planos anteriores que se configuram como importantes instrumentos para a efetivação dos direitos das mulheres.

Os planos têm vigência média de dois anos e caberá a cada um avaliar os resultados obtidos com o plano anterior, corrigindo equívocos, apontando os resultados alcançados e propondo metas para a próxima vigência. São princípios gerais destes planos a igualdade e o respeito à diversidade, a equidade, autonomia das mulheres, universalidade das políticas, efetivação da justiça social e a participação e o controle social. 
Os primeiros capítulos são destinados à autonomia econômica e igualdade no mundo do trabalho, em que são evidenciadas práticas discriminatórias através da somatória das desigualdades étnico-raciais e de gênero e contribuindo para a construção de uma indevida hierarquia de gênero no mercado de trabalho. Apesar desta superioridade, o Plano traçado em 2008 constata um (BRASIL, 2008, online):

"Fenômeno que poderia ser chamado de feminização do mercado de trabalho. De fato, desde o início da década de 1990, é possível verificar um aumento significativo na participação das mulheres nesta esfera. Enquanto em 1996, $52,2 \%$ das mulheres de 16 anos ou mais se encontravam ativas, ou seja, empregadas ou à procura de emprego, este valor alcançou $59 \%$ da população feminina em 2006, um importante acréscimo, ainda mais quando se constata que a taxa de atividade masculina apresentou tendência de queda no mesmo período"

O relatório também aponta que alguns fatores preconceituosos baseados nos estereótipos como a incapacidade para liderança das mulheres e a fragilidade destas fazem com que a remuneração das empregadas seja inferior à dos empregados.

Cabe à Secretaria apoiar projetos estruturantes visando ao emprego e ao empreendedorismo das mulheres, capacitação e assistência técnica, bem como a instituição e o acompanhamento do Programa Pró-Equidade de Gênero que tem como objetivo promover a igualdade de oportunidades e de tratamento entre homens e mulheres nas empresas e promover novas concepções na gestão de pessoas.

\subsection{Os fundamentos esposados no RE 658312}

O relator do recurso extraordinário 658312, que almejava discutir a recepção do artigo 384 da CLT, o relator pondera que o cerne da discussão situa-se sobre a compatibilidade dos artigos. $5^{\circ}$, I e $7^{\circ}, \mathrm{XXX}$ da CRFB/88 com o artigo 384 da CLT que dispõe sobre o necessário intervalo de quinze minutos ao final da jornada de trabalho da mulher, antes do início das horas extraordinárias, sob pena do pagamento de adicional de cinquenta por cento sobre a hora normal.

$\mathrm{O}$ relator afirma que o dispositivo ingressou na ordem jurídica nacional através do Decreto Lei 5.452/43 - CLT - que unificou toda a legislação laboral e criou novos direitos trabalhistas. Prossegue afirmando que, a despeito da previsão da cláusula geral de igualdade em todas as constituições brasileiras, apenas em 1934, foi expressamente prevista a igualdade entre homens e mulheres, sendo repetida nas constituições posteriores.

Todavia, a previsão constitucional da igualdade entre os gêneros não foi suficiente para a concretização da equidade, vindo a CRFB/88 explicitar em três mandamentos distintos a necessária igualdade entre os gêneros, provendo meios para a efetivação progressiva através de políticas públicas e outras ações governamentais e sociais, em nítidas normas programáticas.

A leitura dos dispositivos constitucionais permite concluir que a CRFB adotou alguns critérios legitimadores do tratamento diferenciado entre homens e mulheres, com vistas à promoção da igualdade material. Inicialmente, levou-se em consideração a história exclusão da mulher no mercado de trabalho e impôs ao Estado a necessidade de implantação de políticas públicas de natureza protetiva. O segundo critério adotado, de acordo com o relator, é a existência de componentes biológicos e orgânicos distintos que justificam o tratamento diferenciado e, por derradeiro, a existência de um componente social, "pelo fato de ser comum o acúmulo de atividades pela mulher no lar e no ambiente de trabalho - o que, de fato, é uma realidade e, portanto, deve ser levado em consideração na interpretação da norma."(BRASIL, 2016). Conclui o relator que estes são os critérios que legitimam o tratamento desigual entre homens e mulheres, e, estando a norma atacada, em consonância com um dos critérios de discrímen expostos, teria sido recepcionada pela CRFB. 
Prosseguindo à votação, a Ministra Rosa Weber indica a existência de três correntes doutrinárias acerca do artigo 384 da CLT. A primeira, chamada de teoria negativista, aponta que referido dispositivo não teria sido recepcionado pela $\mathrm{CRFB} / 88$, pois esta assegurou a igualdade de direitos entre homens e mulheres. A segunda, denominada positivista, defende a recepção do artigo 384, posto não haver discriminação ilegítima em função das diferenças físicas e biológicas entre homens e mulheres. Por derradeiro, a corrente ampliativa defende uma leitura extensiva do texto normativo, afirmando que o intervalo de quinze minutos seria devido igualmente para homens e para mulheres. A Ministra indica também diversas hipóteses em que há uma razoável diferenciação entre os sexos, como os testes físicos realizados em concursos para policial militar, em que há exigências menores e a previsão de aposentadoria para a mulher cinco anos mais cedo do que o homem, em razão de seu maior desgaste físico, asseverando que as distinções dizem respeito somente ao "aspecto exterior, não ao interior, no qual a igualdade é reconhecida e até superada."(BRASIL, 2016).

O Ministro Luiz Fux entende haver uma discriminação ilegítima no artigo 384, pontuando que este descanso também deveria ser devido aos empregados do sexo masculino, dado que, como a sociedade atual é eminentemente de serviços, em que prevalece a capacidade intelectual, a distinção física entre os sexos é irrelevante no caso. Aponta, também, que a diferenciação imposta pela CLT acaba por gerar um ônus oculto para o mercado de trabalho em relação às mulheres, apontando que esta norma, a despeito de pretender uma maior proteção às mulheres, viola o direito à igualdade e prejudica seu ingresso e permanência no mercado de trabalho, interpretando o artigo 384 da CLT como constitucional somente naqueles trabalhos em que se exige esforço físico.

O Ministro Gilmar Mendes, mostrando preocupação com o comportamento do mercado de trabalho, afirma que não dispõe de dados suficientes para demonstrar eventual arbitrariedade da norma, entendendo que está em um processo de inconstitucionalização face a modificação gradual da sociedade e, consequentemente, do mercado de trabalho.

Marco Aurélio fundamenta seu voto nos estudos de Alice Monteiro de Barros que constatara anteriormente que leis de cunho tutelar da obreira constituíam obstáculos à contratação de mais mulheres e passaram a ser-lhes prejudiciais. Assim, vislumbra uma discriminação ilegítima, pois maléfica às próprias mulheres, entendendo pela não recepção do dispositivo legal.

Celso de Mello aponta que, no momento de edição da CLT, a norma representou uma expressiva tomada de posição pelo Estado, fortalecendo a posição das mulheres no mercado de trabalho e impondo a necessidade de sua proteção, em reação a uma sociedade patriarcal, opressiva e excludente. Continua afirmando que este direito já se encontra definitivamente consolidado, sendo desarrazoada sua supressão e aduz que a justificação da norma é a proteção à mulher em razão da fragilidade física em relação aos homens.

Vê-se, portanto, que os principais critérios utilizados para o improvimento do recurso extraordinário residem na necessidade de proteção da mulher no mercado de trabalho, dadas diferenças históricas e culturais inegáveis - e já apontadas anteriormente - bem como a diferenças de ordem física e biológica que justificam um tratamento diferenciado em razão do desgaste maior da mulher.

Caberá analisarmos, portanto, se os critérios de discrímen esposados justificam-se, ante a realidade e a ordem jurídico-constitucional vigente e, sobretudo, o alcance da proteção da referida norma e a suficiência de seu critério enquanto norma protetiva das empregadas. 


\section{O CONTEÚDO JURÍDICO DA IGUALDADE E O DISCRÍMEN LEGITIMADOR DE NORMAS DE DESIGUALDADE}

Ao estabelecer a igualdade como um direito de todos e como um dos objetivos fundamentais da República Federativa do Brasil, a CRFB pretendeu igualar a todos ontologicamente, enquanto seres dotados de dignidade independentemente de quaisquer distinções. Todavia, a igualdade preconizada no texto constitucional não é a equidade formal, mas a material, em que são consideradas distinções acidentais sobre os seres humanos que os fazem merecedores de considerações diferentes por parte da sociedade e do poder público. A CRFB traz, portanto, a igualdade com tratamento desigual (DWORKIN, 2007) legitimando diversas ações afirmativas e tratamentos diferenciados a pessoas em situações distintas.

O tratamento discriminatório não é, per si, bom ou ruim; será constitucional ou inconstitucional de acordo com o critério a ser utilizado. A (des)igualdade é relação entre dois ou mais sujeitos em virtude de um critério com vistas a uma determinada finalidade. (ÁVILA, 2008) A mensuração da constitucionalidade de uma medida discriminatória ocorrerá, portanto, com a avaliação do critério de discrímen utilizado, examinando sua proporcionalidade e sua observância aos critérios éticos e axiológicos trazidos pela CRFB/88.

O advento da CLT, no início da década de quarenta, foi um marco na história dos direitos trabalhistas no Brasil, pois serviu como elemento aglutinador de normas esparsas sob um mesmo compêndio e unidos por um substrato axiológico que lhe dá sustentação bem como instituiu novos direitos aos trabalhadores. No tocante aos direitos das empregadas, veio pregar a igualdade entre os gêneros em uma sociedade patriarcal e marcada pela dominação masculina do mercado de trabalho. O capítulo III da legislação consolidada, que trata da proteção do trabalho da mulher, foi elemento importante para o reconhecimento da igualdade de gêneros.

Apesar de o âmbito normativo não se configurar suficiente para as mudanças pretendidas, fatores políticos e sociais alteraram a sociedade brasileira e, nos últimos sessenta anos, vivenciamos um aumento da participação das mulheres no mercado de trabalho, uma superação do número de mulheres com nível superior apesar de ainda haver predominância masculina nos empregos e, em média, terem salários superiores.

O outro fator alegado como legitimador do artigo 384 da CLT foi a diferença fisiológica e física que justificam, por exemplo, aposentadoria antecipada das mulheres em cinco anos e limite de emprego de força muscular a vinte quilos, se trabalho contínuo, e vinte e cinco quilos para o trabalho ocasional, em comparação ao limite de sessenta quilos para os homens.

A instituição de tratamento desigual de forma a concretizar a igualdade material é sempre sensível para o legislador. Trata-se de encontrar um ponto de equilíbrio entre a igualdade e a situação desigual, estando a constitucionalidade da medida dependente de serem encontrados e corrigidos aqueles fatores de diferenciação que, suplantados, elevem a isonomia material almejada pela ordem constitucional.

O que a ordem jurídico-constitucional pretende eliminar é a discriminação sem fatores específicos ou a escolha aleatória, sem pertinência lógica com a diferenciação pretendida. Três questões são necessárias, portanto, para se justificar o tratamento diferenciado com base na autonomia material. O primeiro é o fator de discrímen; o segundo é a correlação lógica abstrata entre o fator de discrímen e o tratamento diferenciado e, por último, a adequação desta correlação lógica aos valores positivados pela ordem constitucional. (MELLO, 2002)

Enquanto os fatores de discrímen já foram apontados no presente trabalho, há que se buscar a relação entre o tratamento diferenciado, qual seja, a instituição de um intervalo de quinze minutos antes do início do horário extraordinário, com a dificuldade de acesso ao mercado de trabalho da mulher e as diferenças físicas existentes entre os sexos. Enquanto, a priori, vislumbra-se uma relação com o segundo fator, há uma dissonância entre o tratamento diferenciado e o objetivo almejado que é o da promoção da igualdade no mercado de trabalho. 
Ao se instituir um tratamento diferenciado e mais custoso para as empregadas, o mercado, eminentemente pragmático e movido sob o viés econômico, preferirá a contratação de homens ou, por outro lado, não chamará mulheres para a prorrogação de jornada. As duas alternativas perpetuarão a realidade atual, quer de uma participação inferior da mulher no trabalho ou a percepção de salários inferiores ao dos homens, em um mesmo posto.

O principal ponto de legitimação de uma norma que confere tratamento desigual, todavia, é a congruência entre os diferentes regimes jurídicos estabelecidos e a desigualdade das situações tratadas. $\mathrm{O}$ fator de discrímen deve ser cuidadosamente analisado, de modo a se conferir validade a uma determinada norma que, a despeito de almejar valores ética e juridicamente positivos, não cumpre o postulado de proporcionalidade ou, tampouco, faz as diferenciações necessários para se preencher o conteúdo do princípio da isonomia material. $\mathrm{O}$ critério de discrímen deverá guardar relação lógica com a diferenciação imposta pela lei. $\mathrm{O}$ entendimento pela recepção do artigo 384 da CLT ocasiona uma manutenção da discriminação e contribuirá para a manutenção da desigualdade entre homens e mulheres. Analisando criticamente disposições relativas ao trabalho da Mulher, Freitas Junior pondera que (FREITAS JUNIOR, 2008, p. 224):

“A regulamentação do trabalho feminino não constitui, ipso facto, reconhecimento ou acolhimento, pela ordem jurídica, das demandas veiculadas na perspectiva da igualdade de oportunidade entre os sexos. Conferindo ao direito do trabalho uma função predominantemente de controle social (...) Antoine Jeammaud oferece importantes advertências contra os riscos de conclusões unilaterais e simplificadoras deste fenômeno. Para este autor, "é necessário simplesmente admitir que todas as disposições ostensivamente favoráveis aos assalariados ocultam um risco para a classe trabalhadora e um cálculo nas estratégias confessas do capital"

Quanto à distinção física existente entre homens e mulheres, a legislação trabalhista e previdenciária prevê normas diferenciadas, como a aposentadoria com tempo de contribuição e idade diferentes e o limite de peso, por exemplo. Estes fatores tornam o trabalho diferente, de acordo com aptidões e capacidades físicas de empregados e empregadas.

À sua promulgação, a CLT proibia o trabalho noturno da mulher e ainda vetou seu emprego em subterrâneos, subsolos, pedreiras e obras, de construção pública ou particular e nas atividades perigosas ou insalubres. A real causa destas proibições não está na incapacidade da mulher para estes trabalhos, mas, ao contrário, da sua utilização como mão de obra barata que é historicamente utilizada nestas atividades.

A evolução social e o advento da CRFB/88 alteraram o paradigma jurídico e econômico do país a ponto de ser uma luta das próprias mulheres a revogação de tais dispositivos celetistas, uma vez que as distinções, quando necessárias, são impostas pela lei (no caso do limite de peso) ou gerenciadas caso a caso, de acordo com aptidões individuais.

As diferenças de cunho biológico apontadas para a justificação das normas diferenciadoras entre homens e mulheres tendem a preservar a integridade física da mulher e suas forças vitais de modo a que a empregada também possa exercer normalmente a função materna (LOPES, 2005). No entanto, toda distinção com base em critérios biológicos deve ser tomada com cautela, não só pela evolução da medicina e sua rápida capacidade de superação de paradigmas, como pela insuficiência de dados disponíveis ao jurista e ao legislador sobre o assunto. O limite de peso imposto pela CLT, por exemplo, não leva em conta diferenças entre os próprios homens e mulheres, como existência de homens franzinos ou mulheres musculosas que facilmente inverteriam a lógica celetista.

Inexiste, também, qualquer elemento comprobatório do maior desgaste físico da mulher, ao final da jornada de trabalho, após as necessárias adaptações já impostas pela legislação. 
O tratamento discriminatório conferido pela CLT não cumpre o objetivo protetivo, limitando ainda mais o acesso da mulher ao mercado de trabalho e dificultando sua ascensão profissional, alimentando uma cultura preconceituosa da suposta fragilidade feminina.

\section{CONCLUSÃO}

A finalização do julgamento do recurso extraordinário n. 658312, em setembro de 2016, pelo Supremo Tribunal Federal, encerrou discussão travada no âmbito da Justiça do Trabalho sobre a legitimidade constitucional do artigo 384 da CLT que prevê um intervalo de quinze minutos ao término da jornada de trabalho da mulher e antes do início da sobrejornada. $\mathrm{O}$ desrespeito ao dispositivo legal ocasiona diversas condenações ao pagamento de adicional de horas extras, que foi um dos principais fundamentos para a repercussão geral e o julgamento do caso pelo STF.

Inicialmente, foi exposto o regime de sobrejornada no direito brasileiro e as inovações trazidas pela Lei 9.601/98 que previu a compensação de horas e foi regulado, posteriormente, o "banco de horas" que prevê a possibilidade de acúmulo de jornada extraordinária para troca por folgas, em um período não superior a um ano. A CLT previa a vedação da realização de horas extras pela empregada, extinguindo-se tal proibição em 1989 quando entendeu pela incompatibilidade desta regra com a igualdade prevista pela CRFB/88.

Esta alteração constituiu um dos primeiros atos estatais cujo primordial objetivo é a promoção da igualdade, sob o prisma axiológica da nova ordem constitucional, sucedido por políticas públicas específicas de estímulo ao empreendedorismo, redução de desigualdades no mercado de trabalho, proibição de atos discriminatórios ilegítimos. Estes atos são frutos de análises periódicas da Secretaria Especial de Políticas para as Mulheres, que traça planos a cada dois anos, fazendo estudos no que fora implementado nos planos anteriores e fazendo projeções para o futuro. Os planos fundamentam-se nos princípios da igualdade e o respeito à diversidade, a equidade, autonomia das mulheres, universalidade das políticas, efetivação da justiça social e a participação e o controle social.

Com o crescimento da participação da mulher no mercado de trabalho, a maior escolaridade, inclusive quando em comparação com os homens, e alterações substanciais no mercado e na sociedade dos últimos setenta anos, cabe a indagação sobre a recepção de normas que preveem tratamento diferenciado para homens e mulheres, sob o fundamento constitucional da igualdade.

O tratamento heteronômico a pessoas consideradas iguais, para ser considerado legítimo, deverá basear-se em um equilíbrio entre os diferentes regimes jurídicos estabelecidos e a desigualdade das situações tratadas. $\mathrm{O}$ fator de discrímen deve ser cuidadosamente analisado, de modo a se conferir validade a uma determinada norma que, a despeito de almejar valores ética e juridicamente positivos, não cumpre o postulado de proporcionalidade ou, tampouco, faz as diferenciações necessários para se preencher o conteúdo do princípio da isonomia material. O critério de discrímen deverá guardar relação lógica com a diferenciação imposta pela lei.

A norma prevista pelo artigo 384 da CLT tem fundamento no preconceito patriarcal no mercado de trabalho e na proteção às mulheres, face a uma fragilidade física da mulher sobre 0 homem.

O primeiro dos argumentos utilizados pelos Ministros do STF no RE 658312 para julgar a recepção do artigo 384 pela $\mathrm{CRFB} / 88$ não encontra relação direta com o tratamento diferenciado. A norma, sob o pretexto de proteger a mulher, acaba por fortalecer o preconceito e contribui para dificultar o acesso ao mercado de trabalho, à ascensão profissional e a equiparação de salários, como apontaram os Ministros Marco Aurélio, Gilmar Mendes e Luiz Fux. O critério de discrímen utilizado não guarda adequação aos fins pretendidos, devendo ser considerado inconstitucional. 
O critério fisiológico e biológico que também justifica outras normas protetivas, como o limite de carregamento de peso pelas empregadas (em até um terço do limite aplicado ao empregado) e as diferenças em tempo de contribuição e idade mínima para aposentadoria não implicam um maior desgaste da mulher durante o trabalho que justifique o intervalo entre o início da sobrejornada. Apesar de haver distinções físicas entre homens e mulheres - que, todavia, não podem ser consideradas de modo amplo e irrestrito - estas distinções são ponderadas por outras normas protetivas que não indicam um maior desgaste da empregada ao término da jornada de trabalho.

A distinção criada pela lei é arbitrária, uma vez que não se baseia em nenhum critério científico ou mesmo comprovação empírica, e gera o efeito contrário pretendido pela lei. A diferença não gera maior proteção à empregada, mas, apenas, aprofunda o abismo preconceituoso, não estimulando a igualdade entre gêneros no mercado de trabalho e nem possibilitando uma ascensão profissional ou maiores ganhos salariais, vez que o mercado operará sempre sob o viés econômico e perpetuará a discriminação de gêneros na sociedade brasileira.

\section{REFERÊNCIAS BIBLIOGRÁFICAS}

ARENDT, Hannah. A Condição humana. Trad. Roberto Raposo. 10 ed. Rio de Janeiro: Forense Universitária, 2007.

ÁVILA, Humberto. Teoria da Igualdade Tributária. São Paulo: Malheiros, 2008.

BARROS, Alice Monteiro. Curso de Direito do Trabalho. 10 ed. São Paulo: LTR, 2016.

BORELLI, Andrea. Aspectos da relação mulher-trabalho na legislação brasileira. 1830-1950. Disponível em:< http://anais.anpuh.org/wp-content/uploads/mp/pdf/ANPUH.S23.0111.pdf>.

BRASL. Índice Súmulas TST. Disponível em: <http://www.tst.jus.br>.

BRASIL. II Plano Nacional de Políticas para as Mulheres. Disponível em:< http://www.observatoriodegenero.gov.br/eixo/politicas-publicas/pnpm/comite-demonitoramento-do-ii-pnpm/Livro_II_PNPM_completo08.10.08.pdf> .

BRASIL. Supremo Tribunal Federal. Acórdão no RE 658312. Disponível em:< http://www.stf.jus.br/arquivo/cms/noticiaNoticiaStf/anexo/RE658312.pdf>

DELGADO, Mauricio Godinho. Curso de Direito do Trabalho. 14 ed. São Paulo: LTR, 2015.

DWORKIN, Ronald. Levando os Direitos a Sério. Trad. Jefferson Luiz Camargo. São Paulo: Martins Fontes, 2007.

FREITAS JUNIOR, Antonio Rodrigues de. O trabalho feminino no Brasil. Revista Jurídica do Trabalho, vol. 1, nº 3, Salvador, out.-dez. 1988.

IBGE. Estatísticas de gênero: uma análise dos resultados do Censo Demográfico 2010. Disponível em: $<$ http://biblioteca.ibge.gov.br/visualizacao/livros/liv88941.pdf $>$. 
LOPES, Cristiane Maria Sbalqueiro. Direito do trabalho da mulher: da proteção à promoção. Disponível em:<http://www.scielo.br/pdf/cpa/n26/30398.pdf>.

MELlO, Celso Antônio Bandeira. O Conteúdo Jurídico do Princípio da Igualdade. 3 ed. São Paulo: Malheiros, 2002.

NASCIMENTO, Amauri Mascaro, FERRARI, Irany, SILVA FILHO, Ives Gandra Martins. História do Trabalho, do Direito do Trabalho e da Justiça do Trabalho. Homenagem a Armando Casimiro Costa. São Paulo: LTR, 2011.

ROCHA, Carmen Lúcia Antunes. Ação afirmativa: o conteúdo jurídico do princípio da igualdade jurídica. In Revista de Informação Legislativa. Brasília. Vol 131. Senado Federal: 1996.

SOUSA, Ana Luísa Andrade de Pinho. O banco de horas individual. Disponível em:< http://repositorio.ucp.pt/bitstream/10400.14/18912/1/Tese\%20de\%20Mestrado\%20Direito\%20do\%20trabalho\%20-\%20Ana\%20Luisa\%20Pinho.pdf>.

WORLD BANK ONLINE. Gender diferences in employment and why they matter. Disponível em: <http://siteresources.worldbank.org/INTWDR2012/Resources/77781051299699968583/7786210-1315936222006/chapter-5.pdf $>$. 